NBER WORKING PAPER SERIES

\title{
INFLATION INERTIA AND CREDIBLE DISINFLATION - THE OPEN ECONOMY CASE
}

\author{
Guillermo Calvo \\ Oya Celasun \\ Michael Kumhof \\ Working Paper 9557 \\ http://www.nber.org/papers/w9557 \\ NATIONAL BUREAU OF ECONOMIC RESEARCH \\ 1050 Massachusetts Avenue \\ Cambridge, MA 02138 \\ March 2003
}

This paper was previously circulated under the title 'Nominal Exchange Rate Anchoring Under Inflation Inertia'. It was completed while Kumhof visited the IMF and the IADB, whose support is gratefully acknowledged. The authors thank Fernando Alvarez, Jeff Campbell, Charles Engel, Timothy Kehoe, Alejandro Micco, Michael Mussa, Lars Svensson, John Taylor, Ken West, and seminar participants at Chicago GSB, Stanford,Wisconsin, the IMF, the IADB, the 2001 NBER Summer Institute, the 2001 Latin American Meetings of the Econometric Society, and the January 2001Winter Camp in Santiago, Chile, for helpful comments. The views expressed herein are those of the authors and not necessarily those of the National Bureau of Economic Research.

(C2003 by Guillermo Calvo, Oya Celasun, and Michael Kumhof. All rights reserved. Short sections of text not to exceed two paragraphs, may be quoted without explicit permission provided that full credit including Cnotice, is given to the source. 
Inflation Inertia and Credible Disinflation - The Open Economy Case

Guillermo Calvo, Oya Celasun, and Michael Kumhof

NBER Working Paper No. 9557

March 2003

JEL No. E31, E52, F41

\section{$\underline{\text { ABSTRACT }}$}

This paper develops a model of inflation inertia based on optimizing forward looking staggered price setting in a small open economy. Unlike in current models of sticky prices, transitions to a lower steady state inflation rate take time even if they are fully credible, and they are associated with significant output losses. There is a welfare trade-off between these output losses and the gains from smaller inflationary distortions. For reasonable parameter values inflation stabilization improves welfare. The optimal steady state is reached at the Friedman rule.

Technical appendices are available at www.nber.org/data-appendix/w9557/inert-techapp.pdf

Guillermo A. Calvo

Chief Economist

The Inter-American Development Bank

1300 New York Avenue NW

Washington, DC 20577

Michael Kumhof

Department of Economics

Stanford University

579 Serra Mall

Stanford, CA 94305
Oya Celasun

Research Department

The International Monetary Fund

$70019^{\text {th }}$ Street NW

Washington, DC 20431 


\section{Introduction}

An expanding literature on monetary policy analysis uses optimizing dynamic general equilibrium models in which forward-looking agents face nominal rigidities. This literature builds on the original time-dependent price adjustment formulations of Taylor (1980), Rotemberg (1982) and Calvo (1983). ${ }^{1} \quad$ The renewed interest in this line of research was motivated by empirical evidence showing that monetary policy has significant short-run real effects. ${ }^{2}$ But whether the inflation specifications derived from such models can fully account for all short-run empirical properties of inflation and output has recently been much debated. ${ }^{3}$ In particular, starting with Fuhrer and Moore (1995), existing rational expectations staggered pricing models in which agents have perfect information have been shown to display a much lower degree of inflation inertia than what is found in the data. This in turn implies that disinflation policies have minimal real costs, or even that anticipated disinflations cause booms (Ball, 1994a), which is also inconsistent with a large body of empirical evidence (see e.g. Gordon 1982, 1997). This paper proposes a tractable generalization of the Calvo (1983) staggered pricing model that generates both inflation inertia and recessionary disinflations in a fully specified dynamic general equilibrium model.

\footnotetext{
1 Comprehensive surveys can be found in Gali (2001) and Lane (2001).

2 See, for example, Christiano, Eichenbaum and Evans (1996, 1998) and Leeper, Sims and Zha (1996).

3 See Taylor (1998) and Clarida, Gali and Gertler (1999) for a review of the empirical successes of this model class.
} 
Our model retains the commonly used Calvo (1983) assumption of exogenous and stochastic timing of price changing opportunities. Where we depart from the existing literature is in the specification of price setting behavior. In the realistic case of a positive steady state inflation rate, we suggest that it is plausible to assume that firms employ pricing rules which keep them as close as possible to their flexible price optimum without incurring reoptimization costs. To keep the model tractable, we specifically assume that once a firm gets the chance to change its pricing plan, it jointly and optimally chooses an initial price level and a rate at which it will update its price in the future, a 'firm-specific inflation rate'. ${ }^{4}$ This approach differs from the two dominant approaches in the literature. In one (e.g. Woodford , 2001) firms choose only a price level without updating. At positive steady state inflation this has been shown to generate a monetary nonneutrality (Rotemberg and Woodford,1998) where higher steady state inflation implies lower steady state output through increased price dispersion. This nonneutrality is removed in the second approach, starting with Yun (1996), where firms still choose only a price level but update their prices at the steady state inflation rate at all times. ${ }^{5}$ But under both of these approaches only the aggregate price level is sticky while inflation is flexible. Credible disinflations therefore do not cause recessions.

By contrast, when firms employ pricing rules of the kind we propose, an unexpected and permanent decline in the steady state inflation rate targeted by monetary policy entails a slow

\footnotetext{
4 As our pricing rule does not take the simple form of setting new price levels, it is important to stress that our motivation for time dependent nominal rigidities is not based on menu costs (Akerlof and Yellen (1985)) but instead on reoptimization costs, such as costs of information gathering, decision making, negotiation and communication. The empirical evidence presented by Zbaracki, Ritson, Levy, Dutta and Bergen (2000) emphasizes the importance of such reoptimization costs relative to menu costs. Christiano et al. (2001) also stress the reoptimization cost motivation.

5 As we allow for updating, our model also removes the nonneutrality.
} 
inflation response and output losses, even if the change in policy is perfectly credible. There are two main reasons for this. The first is the lingering effect of historic pricing decisions. The economy initially contains a large number of firms that have chosen their price updating rates under the previous policy, and the weighted average of such updating rates is an important component of aggregate inflation. The second reason is the behavior of new price setters. The spread between firms' initially chosen price and the aggregate price level—termed front loading by Christiano et al. (2001) - is the second component of aggregate inflation. Because firms have the option of updating their prices, front loading will initially respond little to the policy change, contributing to the sluggishness of the inflation response. Finally, the real interest rate change induced by the slow inflation response gives rise to a recession. ${ }^{6}$

The motivation for our work was first developed in Calvo, Celasun and Kumhof (2001), and is similar to that of Mankiw and Reis (2002). The latter present a model where price setters are assumed to be able to reset their price every period, but receive information only at random intervals. This is equivalent to assuming that firms choose a price path, and it implies that aggregate inflation responds to monetary policy changes with a lag and that disinflations are recessionary. The Mankiw and Reis (2002) model is capable of generating predictions that qualitatively match the inflation inertia and recessionary disinflations features of the data. Its drawback, however, is that the model's microeconomic foundations are not fully laid out, which makes it harder to explore

\footnotetext{
${ }_{6}$ Empirical tests of the pricing model based on Mexican data, and reported in Calvo, Celasun and Kumhof (2001), are supportive of our inflation specification, suggesting that our formulation is a sensible way of capturing inflation inertia in similar countries.
} 
its quantitative predictions and their sensitivity to the values of structural parameters. It is therefore also not possible to conduct welfare analysis. The general equilibrium model of Burstein (2002) can be seen as a way of providing microeconomic foundations for the Mankiw and Reis (2002) formulation. ${ }^{7}$ However it is a nonlinear model and therefore complex to solve. We argue that it is reasonable to focus on equilibria characterized by a constant steady state growth path for the nominal anchor. The model can then be solved by linearizing around that steady state. In that case it is sufficient to allow firms to specify their pricing policies up to the growth rate of their price path. A considerable advantage of this approach is that our model can be solved with conventional solution methods, which makes it straightforward to conduct quantitative work including welfare analysis, as will be shown in Section 4.

The literature related to inflation inertia also encompasses models of backward-looking behavior, imperfect credibility, learning and supply side rigidities. Until quite recently the literature mostly relied on specifications that were not explicitly built on forward-looking optimizing behavior. Fuhrer and Moore (1995) present a relative real wage model, while Ghezzi (2001) and Clarida, Gali and Gertler (1999) modify the Calvo (1983) model to allow for a share of price setters to be backward looking, in the sense of using a rule of thumb that depends on lagged inflation. A well-known explanation for inflation inertia during disinflations is lack of credibility, e.g. the papers by Ball (1995) and Calvo and Vegh (1993). However, in many countries where disinflations were costly the monetary authority enjoyed a high degree of credibility, as argued e.g. by Ball

\footnotetext{
7 In Burstein's (2002) model pricing decisions are state- as well as time-dependent, but a pure time dependent model is shown to be sufficient to characterize disinflationary dynamics when the disinflation is not too large.
} 
(1994b). This is therefore only a suitable explanation for a limited number of cases. Models of learning about monetary policy have recently become popular, and clearly such models do give rise to inflation inertia. Two examples are Woodford (2001) and Erceg and Levin (2002). Christiano, Eichenbaum and Evans (2001) generate inflation and output inertia in a rational expectations model by introducing a number of nominal and real supply side rigidities. Their most successful model variant does however still rely on a backward-looking price and wage updating scheme.

The pricing mechanism we propose is very general and can be embedded in a variety of macroeconomic models. The key features of inflation inertia and recessionary disinflations are robust across such environments. ${ }^{8}$ For this paper we choose an open economy setting, and for our specification of disinflationary monetary policy we choose exchange rate targeting. ${ }^{9} \quad$ The disinflations we have in mind are the moderate disinflations experienced by several industrialized countries in the 1970s and 1980s, and by a number of countries in Latin America in more recent years. $^{10}$

The rest of the paper is organized as follows. Section 2 presents the model. Section 3 discusses model calibration and computation of solution paths for a permanent and credible disinflation. Section 4 evaluates the welfare trade-off between the output losses and efficiency

\footnotetext{
8 For example, Kumhof, Cespedes and Parrado (2002) analyze the closed economy case in a discrete time stochastic setting.

9 A model of inflation targeting is analytically more complex while displaying very similar qualitative features.

10 Historically, many exchange rate based stabilizations of very high inflation have been characterized by an initial consumption boom followed by a later recession, see Calvo and Vegh (1999) for a survey. Our model does not incorporate elements that could generate such a boom, such as lack of credibility or wealth effects. Our result that inflation inertia by itself leads to an initial recession is consistent with Calvo and Vegh (1994), who posit a wage setting equation that is not derived from optimization.
} 
gains of disinflation. Section 5 concludes. Some technical details and proofs are contained in two appendices. ${ }^{11}$

\section{The Model}

Consider a small open economy which consists of a government, a continuum of measure one of identical price-taking infinitely-lived households, and a continuum, indexed by $j \in[0,1]$, of monopolistically competitive infinitely-lived nontradable goods producing firms. The economy trades goods with the rest of the world, and for the prices of these tradable goods purchasing power parity is assumed to hold. Normalizing the foreign price level to one this implies that the nominal price of tradables equals the nominal exchange rate $E_{t}$. The nominal price level of nontradable goods is denoted by $P_{t}$, and the associated inflation rate by $\pi_{t}=\dot{P}_{t} / P_{t}$. The relative price of tradables and nontradables, which will be referred to as the real exchange rate, is $e_{t}=E_{t} / P_{t}$. The economy can also freely borrow from or lend to the rest of the world, and uncovered interest parity is assumed to hold:

$$
i_{t}=r+\varepsilon_{t} .
$$

Here $r$ is the exogenous, constant and positive real international interest rate, $\varepsilon_{t}=\dot{E}_{t} / E_{t}$ is the rate of exchange rate depreciation, and $i_{t}$ is the nominal interest rate on domestic currency denominated assets.

\footnotetext{
11 An additional appendix with detailed derivations of all key equations is available from the authors upon request.
} 


\section{Households}

Households maximize lifetime utility, which depends on their consumption of homogenous tradable goods $c_{t}^{*}$, heterogeneous nontradable goods $c_{t}(j), j \in[0,1]$, and utility from leisure $1-L_{t}$, where 1 is the fixed endowment of time and $L_{t}$ is total labor supply to firms. To rule out inessential dynamics households' personal discount rate is assumed to equal the real return $r$ on international bonds denominated in units of tradable goods $b_{t}$. Aggregate nontradables consumption is given by

$$
c_{t}=\left(\int_{0}^{1} c_{t}(j)^{\frac{\sigma-1}{\sigma}} d j\right)^{\frac{\sigma}{\sigma-1}},
$$

with elasticity of substitution $\sigma>1$. Let $P_{t}(j)$ be the price of individual good $c_{t}(j)$. Then cost minimization implies

$$
c_{t}(j)=c_{t}\left(\frac{P_{t}(j)}{P_{t}}\right)^{-\sigma},
$$

where the price index of nontradables $P_{t}$ is

$$
P_{t}=\left(\int_{0}^{1} P_{t}(j)^{1-\sigma} d j\right)^{\frac{1}{1-\sigma}} .
$$

The representative household's objective function is

$$
\operatorname{Max} \int_{0}^{\infty}\left[\gamma \ln \left(c_{t}^{*}\right)+(1-\gamma) \ln \left(c_{t}\right)+\kappa \ln \left(1-L_{t}\right)\right] e^{-r t} d t .
$$

Households are subject to a cash in advance constraint for their purchases of tradables and nontradables:

$$
m_{t} \geq \alpha\left(c_{t}^{*}+\frac{c_{t}}{e_{t}}\right) .
$$

Here $m_{t}\left(M_{t}\right)$ are real (nominal) money balances, with $m_{t}=M_{t} / E_{t}$, and $\alpha$ is constant inverse 
velocity. The opportunity cost of holding one unit of money is equal to the nominal interest rate, which given our assumption of predetermined positive exchange rate depreciation (see below) and uncovered interest parity must be greater than zero. The cash-in-advance constraint will therefore be binding at all times. Households receive a fixed endowment of tradable goods $y^{*}$, and government lump-sum transfers in terms of tradables $\tau_{t}$. From firms they receive nominal wages $W_{t} L_{t}$ and nominal lump-sum profit distributions $\int_{0}^{1} \Pi_{t}(j) d j$. Their flow budget constraint is

$$
\dot{b}_{t}=r b_{t}-\dot{m}_{t}-\varepsilon_{t} m_{t}+y^{*}-c_{t}^{*}+\tau_{t}+\frac{W_{t} L_{t}}{E_{t}}+\frac{\int_{0}^{1} \Pi_{t}(j) d j}{E_{t}}-\frac{\int_{0}^{1} P_{t}(j) c_{t}(j) d j}{E_{t}} .
$$

After imposing the no Ponzi games condition $\lim _{t \rightarrow \infty}\left(b_{t}+m_{t}\right) e^{-r t} \geq 0$, we can write their lifetime budget constraint as

$$
\begin{aligned}
& b_{0}+m_{0}+\int_{0}^{\infty}\left(y^{*}+\tau_{t}+\frac{W_{t} L_{t}}{E_{t}}+\frac{\int_{0}^{1} \Pi_{t}(j) d j}{E_{t}}\right) e^{-r t} d t \\
\geq & \int_{0}^{\infty}\left(c_{t}^{*}+\frac{\int_{0}^{1} P_{t}(j) c_{t}(j) d j}{E_{t}}+i_{t} m_{t}\right) e^{-r t} d t .
\end{aligned}
$$

The representative household maximizes (5) subject to (6) and (8), with (6) binding. The first order conditions are (8) holding with equality, (3) and

$$
\begin{gathered}
\frac{\gamma}{c_{t}^{*}}=\lambda\left(1+\alpha i_{t}\right), \\
\frac{c_{t}}{c_{t}^{*}}=e_{t} \frac{1-\gamma}{\gamma}, \\
w_{t} \equiv \frac{W_{t}}{P_{t}}=\frac{\kappa c_{t}\left(1+\alpha i_{t}\right)}{\left(1-L_{t}\right)(1-\gamma)} .
\end{gathered}
$$


Here $\lambda$ is the constant multiplier of the lifetime budget constraint (8), equal to the shadow value of lifetime wealth. Equation (9) equates the marginal utility of tradables consumption to the marginal utility of wealth times the effective price of consumption, the latter being equal to the purchase price plus the cost of holding the money balances necessary to conduct transactions. Equation (10) equates the marginal rate of substitution between tradables and nontradables to their relative price, the real exchange rate. Equation (11) equates the real wage to the marginal rate of substitution between consumption and leisure, corrected for a monetary distortion. The latter is increasing in deviations from the Friedman rule.

\section{Firms}

Firms in the nontradables sector are distributed uniformly along the unit interval and have linear production functions in labor input $l_{t}(j)$ :

$$
y_{t}(j)=l_{t}(j), \quad j \in[0,1]
$$

They are price takers in the labor market and monopolistically competitive in the goods market. Firms distribute all nominal profits $\Pi_{t}(j)$ to households in a lump-sum fashion:

$$
\Pi_{t}(j)=P_{t}(j) c_{t}(j)-W_{t} l_{t}(j), \quad j \in[0,1]
$$

Following Calvo (1983), it is assumed that firms only get infrequent opportunities to change their prices, and that these opportunities arrive as exogenous random processes. For each firm they follow an exponential distribution with probability density $\delta e^{-\delta t}$, and are therefore independent

of their last occurrence. They are also independent across firms. This allows the application of 
a law of large numbers and implies that firm-specific uncertainty does not translate into income uncertainty for the representative household.

Firms maximize the present discounted value of real future profits each time they are allowed to change prices. Their discount rate is the own rate of interest for nontradable goods $r+\varepsilon_{t}-\pi_{t}$, and in addition they weight profits at each future time by the probability that today's price will still be in force. Firms' real marginal cost equals the real wage in terms of nontradables $w_{t}=W_{t} / P_{t}$, where $W_{t}$ and $P_{t}$ are taken as given. Firms receive a proportional output subsidy $s u b=(\sigma-1)^{-1}$ from the government. This offsets the steady state markup distortion that arises under monopolistic competition (see e.g. Woodford (2002)). Crucially for this paper, whenever firms do receive a price changing opportunity they determine an optimal price schedule, consisting of today's price level $V_{t}^{j}$ and a firm specific inflation rate $v_{t}^{j}$. If the price schedule of product variety $j$ was last set at time $t$, we therefore have for all $s>t$ that

$$
P_{s}(j)=V_{t}^{j} e^{v_{t}^{j}(s-t)}
$$

Firms maximize

$$
\underset{V_{t}^{j}, v_{t}^{j}}{\operatorname{Max}} \int_{t}^{\infty} e^{-\int_{t}^{s}\left(\delta+r+\varepsilon_{r}-\pi_{r}\right) d r}\left[\frac{V_{t}^{j} e^{v_{t}^{j}(s-t)}}{P_{s}} y_{s}(j)(1+s u b)-w_{s} l_{s}(j)\right] d s,
$$

subject to the production function (12), and subject to goods demand (3). Given (14) the goods demand can, for $s>t$, be written as

$$
y_{s}(j)=c_{s}\left(\frac{V_{t}^{j} e^{v_{t}^{j}(s-t)}}{P_{s}}\right)^{-\sigma} .
$$

Note that the maximization problem is identical for all firms that receive a price changing 
opportunity, so that the firm index $j$ can be dropped in stating the first order conditions. For $V_{t}$ we have

$$
\int_{t}^{\infty} e^{-\int_{t}^{s}\left(\delta+r+\varepsilon_{r}-\pi_{r}\right) d r} c_{s}\left(\frac{V_{t} e^{v_{t}(s-t)}}{P_{s}}\right)^{-\sigma}\left[\frac{V_{t} e^{v_{t}(s-t)}}{P_{s}}-w_{s}\right] d s=0
$$

We define the new variable $p_{t} \equiv V_{t} / P_{t}$, the initial relative price of new price setters. Note also that, for $s>t, P_{s}=P_{t} e^{\int_{t}^{s} \pi_{r} d r}$. Then we can rewrite the last condition as

$$
\int_{t}^{\infty} e^{-\int_{t}^{s}\left(\delta+r+\varepsilon_{r}-\pi_{r}\right) d r} c_{s}\left(p_{t} e^{-\int_{t}^{s}\left(\pi_{r}-v_{t}\right) d r}\right)^{-\sigma}\left[p_{t} e^{-\int_{t}^{s}\left(\pi_{r}-v_{t}\right) d r}-w_{s}\right] d s=0
$$

Steady state values will be denoted by a bar above the respective variable. Note that in steady state, for a constant rate of exchange rate depreciation $\bar{\varepsilon}$, we must have $\bar{\pi}=\bar{v}=\bar{\varepsilon}$ and $\bar{p}=1$. The steady state real wage therefore follows from (17) as $\bar{w}=1$. The first-order condition for $v_{t}$ is

$$
\int_{t}^{\infty} e^{-\int_{t}^{s}\left(\delta+r+\varepsilon_{r}-\pi_{r}\right) d r} c_{s}\left(p_{t} e^{-\int_{t}^{s}\left(\pi_{r}-v_{t}\right) d r}\right)^{-\sigma}(s-t)\left[p_{t} e^{-\int_{t}^{s}\left(\pi_{r}-v_{t}\right) d r}-w_{s}\right] d s=0
$$

Next we linearize (17) and (18) around the steady state. ${ }^{12}$ The following expressions are obtained:

$$
\begin{gathered}
p_{t}+\frac{v_{t}}{\delta+r}=(\delta+r) \int_{t}^{\infty} e^{-(\delta+r)(s-t)}\left[w_{s}+\int_{t}^{s} \pi_{r} d r\right] d s=0 \\
\frac{p_{t}}{\delta+r}+\frac{2 v_{t}}{(\delta+r)^{2}}=(\delta+r) \int_{t}^{\infty} e^{-(\delta+r)(s-t)}(s-t)\left[w_{s}+\int_{t}^{s} \pi_{r} d r\right] d s=0 .
\end{gathered}
$$

The derivatives with respect to time of these expressions are

$$
\dot{p}_{t}+\frac{\dot{v}_{t}}{\delta+r}=(\delta+r)\left(p_{t}-w_{t}\right)+v_{t}-\pi_{t}
$$

\footnotetext{
12 In the following derivations we make use of the following two properties of exponential distributions: $\delta \int_{t}^{\infty}(s-$ $t) e^{-\delta(s-t)} d s=\frac{1}{\delta}, \delta \int_{t}^{\infty}(s-t)^{2} e^{-\delta(s-t)} d s=\frac{2}{\delta^{2}}$.
} 


$$
\dot{p}_{t}+\frac{2 \dot{v}_{t}}{\delta+r}=v_{t}-\pi_{t}
$$

We combine (21) and (22) to obtain the following differential equation for the firm-specific inflation rate $v_{t}$ :

$$
\dot{v}_{t}=-(\delta+r)^{2}\left(p_{t}-w_{t}\right)
$$

It is clear that $v_{t}$ is a jump variable. When there is a discrete change in the monetary policy regime it will be optimal for firms receiving a price changing signal to allow discrete changes in both their current price and their firm specific inflation rate.

To complete the description of price dynamics we now turn to the aggregate price index. When firms set prices in the manner specified above, the index (4) can be rewritten as

$$
P_{t}=\left(\delta \int_{-\infty}^{t} e^{-\delta(t-s)}\left(V_{s} e^{v_{s}(t-s)}\right)^{1-\sigma} d s\right)^{\frac{1}{1-\sigma}}
$$

To obtain an expression for the aggregate inflation rate we first take the derivative of (24) with respect to time. We obtain:

$$
\pi_{t}=\frac{\delta}{1-\sigma}\left(p_{t}^{1-\sigma}-1\right)+\delta \int_{-\infty}^{t} e^{-\delta(t-s)}\left(p_{s} e^{-\int_{s}^{t}\left(\pi_{r}-v_{s}\right) d r}\right)^{1-\sigma} v_{s} d s
$$

Next we linearize this expression around the steady state:

$\left(\pi_{t}-\bar{\varepsilon}\right)=\delta\left(p_{t}-1\right)+\delta \int_{-\infty}^{t} e^{-\delta(t-s)}\left[\left(v_{s}-\bar{\varepsilon}\right)+\bar{\varepsilon}(1-\sigma)\left(\left(p_{s}-1\right)-\int_{s}^{t}\left(\pi_{r}-v_{s}\right) d r\right)\right] d s$

This expression can be simplified by realizing that the price index (24) can, after applying the 
normalization introduced for (17) and (18), itself be linearized as

$$
\delta \int_{-\infty}^{t} e^{-\delta(t-s)}(1-\sigma)\left(\left(p_{s}-1\right)-\int_{s}^{t}\left(\pi_{r}-v_{s}\right) d r\right) d s=0
$$

Substituting this expression into (26) we obtain

$$
\left(\pi_{t}-\bar{\varepsilon}\right)=\delta\left(p_{t}-1\right)+\delta \int_{-\infty}^{t} e^{-\delta(t-s)}\left(v_{s}-\bar{\varepsilon}\right) d s .
$$

We now define a new variable $\psi_{t}$ as the weighted average of currently 'active' firm-specific inflation rates

$$
\psi_{t}=\delta \int_{-\infty}^{t} e^{-\delta(t-s)} v_{s} d s
$$

This variable is predetermined, and its time derivative is

$$
\dot{\psi}_{t}=\delta\left(v_{t}-\bar{\varepsilon}\right)-\delta\left(\psi_{t}-\bar{\varepsilon}\right)
$$

Using the definition of $\psi_{t}$ we can rewrite the expression for aggregate inflation as

$$
\left(\pi_{t}-\bar{\varepsilon}\right)=\delta\left(p_{t}-1\right)+\left(\psi_{t}-\bar{\varepsilon}\right)
$$

This is a key equation. The second term reflects inertia in the aggregate inflation rate through the historic pricing policies of firms which have not yet received a price changing opportunity. The first term, the initial relative price of new price setters $p_{t}$, is free to jump at time 0 . Therefore, despite the presence of an inertial component, aggregate inflation is a free or jump variable. Its derivative with respect to time is found, after some algebra, to equal

$$
\dot{\pi}_{t}=-(3 \delta+2 r)\left(\psi_{t}-\bar{\varepsilon}\right)+2 \delta\left(v_{t}-\bar{\varepsilon}\right)+(\delta+2 r)\left(\pi_{t}-\bar{\varepsilon}\right)-2 \delta(\delta+r)\left(w_{t}-1\right)
$$

Expression (31) can also be used to rewrite the differential equation for firm-specific inflation 
as

$$
\dot{v}_{t}=\frac{(\delta+r)^{2}}{\delta}\left(\psi_{t}-\bar{\varepsilon}\right)-\frac{(\delta+r)^{2}}{\delta}\left(\pi_{t}-\bar{\varepsilon}\right)+(\delta+r)^{2}\left(w_{t}-1\right)
$$

The system of differential equations (30), (32) and (33) in $\psi, \pi$ and $v$ must be closed with a fourth equation for real marginal cost $w$, derived from (11), to fully characterize the dynamic behavior of this economy. To do so we must first describe government behavior and define equilibrium.

\section{Government}

The government owns a stock of net foreign assets $h_{t}$, issues money $M_{t}$, and makes lump-sum transfers $\tau_{t}$. Its flow budget constraint is

$$
\dot{h}_{t}=r h_{t}+\dot{m}_{t}+\varepsilon_{t} m_{t}-\tau_{t}-s u b\left(c_{t} / e_{t}\right)
$$

where we have used the fact that $\int_{0}^{1}\left(\frac{P_{t}(j) y_{t}(j)}{E_{t}}\right) d j=\frac{c_{t}}{e_{t}}$. By imposing the transversality condition $\lim _{t \rightarrow \infty}\left(h_{t}-m_{t}\right) e^{-r t}=0$ one obtains the government's lifetime constraint

$$
h_{0}-m_{0}+\int_{0}^{\infty}\left(i_{t} m_{t}-\tau_{t}-s u b\left(c_{t} / e_{t}\right)\right) e^{-r t} d t=0
$$

A government policy is defined as a list of time paths $\left\{E_{t}, \tau_{t}\right\}_{t=0}^{\infty}$ such that, given the time paths $\left\{m_{t}, c_{t}, P_{t}\right\}_{t=0}^{\infty}$, the constraint (34) holds. In particular, fiscal policy $\left\{\tau_{t}\right\}_{t=0}^{\infty}$ is assumed to be Ricardian. As for exchange rate policy $\left\{E_{t}\right\}_{t=0}^{\infty}$, we assume that the government reduces inflation by a surprise announcement at time 0 of a permanently lower rate of exchange rate depreciation:

$$
\begin{aligned}
& \varepsilon_{t}=\varepsilon^{h}, t \in(-\infty, 0), \\
& \varepsilon_{t}=\varepsilon^{l}, t \in[0, \infty) .
\end{aligned}
$$




\section{Equilibrium}

The list of time paths $\left\{b_{t}, h_{t}, m_{t}, c_{t}^{*}, y_{t}^{*}, L_{t}, c_{t}, y_{t}, l_{t}(j), c_{t}(j), y_{t}(j), j \in[0,1]\right\}_{t=0}^{\infty}$ is an allocation, with the relationship between $c_{t}$ and $c_{t}(j)$ given by (2). A price system is a list of time paths $\left\{P_{t}, W_{t}, P_{t}(j), V_{t}^{j}, v_{t}^{j}, j \in[0,1]\right\}_{t=0}^{\infty}$, with the relationship between $P_{t}$ and $P_{t}(j)$ given by (4) and the relationship between $P_{t}(j), V_{t}^{j}$ and $v_{t}^{j}$ given by (14). Finally let $f_{t}=b_{t}+h_{t}$, the economy's overall level of net foreign assets. Then equilibrium is defined as follows:

A perfect foresight equilibrium given $f_{0}$ is an allocation, a price system, and a government policy such that (a) given the government policy and the price system, the allocation solves the household's problem of maximizing (5) subject to (6) and (8), with (6) binding, (b) given the government policy, the restrictions on price setting, and the sequences $\left\{P_{t}, W_{t}, c_{t}\right\}_{t=0}^{\infty}$, the

sequences $\left\{V_{t}^{j}, v_{t}^{j}, y_{t}(j), l_{t}(j), j \in[0,1]\right\}_{t=0}^{\infty}$ solve firms' problem of maximizing (15) subject to (12) and (16),

(c) the nontradable goods market clears for all goods and at all times,

$$
y_{t}(j)=c_{t}(j) \quad \forall t, \forall j \in[0,1] \quad,
$$

(d) the labor market clears at all times,

$$
L_{t}=\int_{0}^{1} l_{t}(j) d j \quad \forall t .
$$

Equations (34), (8) holding with equality, and the definition of equilibrium imply that the following aggregate budget constraint must hold:

$$
f_{0}+\frac{y^{*}}{r}=\int_{0}^{\infty} c_{t}^{*} e^{-r t} d t
$$


Combining this constraint with the first order condition (9) one can derive the path of tradables consumption. This is trivial for the case of a constant nominal interest rate such as in our assumed permanent stabilization policy, which features a constant predetermined exchange rate depreciation path. We have

$$
c_{t}^{*}=y^{*}+r f_{0} \quad \forall t
$$

Note that, even for the more general disinflation policies discussed in Section 4, the equilibrium paths of tradables consumption and therefore of net foreign assets can be computed independently from the rest of the economy because they are functions only of endowments $\left(f_{0}\right.$ and $\left.y^{*}\right)$ and of exogenous world and policy variables $\left(r\right.$ and $\left.\varepsilon_{t}\right)$. This is useful in computing the equilibrium of the nontradable goods market.

\section{Complete Dynamic System}

The results of the previous subsection can be used to derive a differential equation for real marginal cost $w$ from (11). We begin by linearizing the equation around the steady state, obtaining

$$
\left(w_{t}-1\right)=\left(\ln c_{t}-\ln \bar{c}\right)+\frac{\alpha}{1+\alpha \bar{\imath}}\left(\varepsilon_{t}-\bar{\varepsilon}\right)+\frac{\bar{L}}{1-\bar{L}}\left(\ln L_{t}-\ln \bar{L}\right) .
$$

To make further progress we have to establish a relationship between $c$ and $L$. It is shown in Appendix A that $\bar{L}=\bar{c}$ and that, after linearizing, one obtains

$$
\ln L_{t}-\ln \bar{L}=\ln c_{t}-\ln \bar{c} .
$$

Therefore (40) simplifies to

$$
\left(w_{t}-1\right)=\frac{1}{1-\bar{c}}\left(\ln c_{t}-\ln \bar{c}\right)+\frac{\alpha}{1+\alpha \bar{\imath}}\left(\varepsilon_{t}-\bar{\varepsilon}\right) .
$$


Note that steady state nontradables consumption $\bar{c}$ is a strictly decreasing function of the exogenous steady state nominal interest rate $\bar{\imath}$. This reflects the negative effect of deviations from the Friedman rule on steady state output, which will play an important part in the welfare analysis. It can be seen in the steady state version of (11):

$$
\bar{c}=\frac{(1-\gamma)}{(1-\gamma)+\kappa(1+\alpha \bar{\imath})} .
$$

Next we linearize equation (10) to obtain the first term of equation (42):

$$
\left(\ln \left(c_{t}\right)-\ln (\bar{c})\right)=\left(\ln \left(c_{t}^{*}\right)-\ln \left(\bar{c}^{*}\right)\right)+\left(\ln \left(e_{t}\right)-\ln (\bar{e})\right)
$$

To derive a differential equation for $w_{t}$ note first that, given (9) and our assumptions about government policy, exchange rate depreciation and the tradables consumption profile satisfy $\dot{\varepsilon}_{t}=0$ and $\dot{c}_{t}^{*}=0$. Secondly, for the real exchange rate we have

$$
\left(\stackrel{\bullet}{\ln e_{t}}\right)=\varepsilon_{t}-\pi_{t}
$$

Therefore we finally obtain

$$
\dot{w}_{t}=-\left(\frac{1}{1-\bar{c}}\right)\left(\pi_{t}-\bar{\varepsilon}\right)+\left(\frac{1}{1-\bar{c}}\right)\left(\varepsilon_{t}-\bar{\varepsilon}\right) .
$$

This equation says that a real appreciation, i.e. a rising relative price of nontradables, is associated with a fall in real wages in the nontradables sector. The reason is that the higher relative price lowers the demand for nontradables output and therefore for labor, which depresses the real wage.

We now show that $w_{t}$ is a predetermined variable. Consider equation (42) and the possibility of jumps at time 0 . The excess demand component is decomposed in (44). The real exchange 
rate is predetermined under predetermined nominal exchange rates and sticky prices, while the tradables consumption path is a function only of exogenous lifetime resources and government policies. This makes excess demand a predetermined variable. See Ghezzi (2001) and Calvo and Vegh (1994) for similar arguments. Jumps in $\varepsilon_{t}$ in equation (42) are also exogenous. Therefore $w_{t}$ is a predetermined variable, along with $\psi_{t}$. The variables $v_{t}$ and $\pi_{t}$ are free to jump at time 0 . The full dynamic system for this economy is represented by equations (30), (33), (32) and (46). In matrix form it looks as follows:

$$
\left[\begin{array}{c}
\dot{\psi}_{t} \\
\dot{v}_{t} \\
\dot{\pi}_{t} \\
\dot{w}_{t}
\end{array}\right]=\left[\begin{array}{cccc}
-\delta & \delta & 0 & 0 \\
\frac{(\delta+r)^{2}}{\delta} & 0 & -\frac{(\delta+r)^{2}}{\delta} & (\delta+r)^{2} \\
-(3 \delta+2 r) & 2 \delta & (\delta+2 r) & -2 \delta(\delta+r) \\
0 & 0 & -\frac{1}{1-\bar{c}} & 0
\end{array}\right]\left[\begin{array}{c}
\left(\psi_{t}-\bar{\varepsilon}\right) \\
\left(v_{t}-\bar{\varepsilon}\right) \\
\left(\pi_{t}-\bar{\varepsilon}\right) \\
\left(w_{t}-1\right)
\end{array}\right]+\left[\begin{array}{c}
0 \\
0 \\
0 \\
\frac{1}{1-\bar{c}}
\end{array}\right]\left(\varepsilon_{t}-\bar{\varepsilon}\right) .
$$

In Appendix B we prove that this system has two eigenvalues with positive real parts and two with negative real parts. Given our results about the number of predetermined variables this proves that the system is saddle path stable. It can further be shown numerically that for a very large range of relevant parameter values ${ }^{13}$ all roots are real.

\section{Model Solution and Discussion}

\section{Calibration}

In this section we compute solution paths for the model after assigning the parameter values shown in Table 1. The time unit for calibration of stock-flow ratios is one quarter. We consider a relatively moderate disinflation from $20 \%$ to $10 \%$, which is of the order of magnitude of several recent and current Latin American disinflations. The parameters $\alpha$ and $r$ are calibrated based on

\footnotetext{
13 We searched over $\delta \in[0.05,2]$, leaving all other values at those used below in the calibrations.
} 
sample averages for Brazil between the beginning of 1995 and the end of 1998, corresponding to the main period of that country's exchange rate based disinflation plan. Inverse velocity $\alpha$ is set equal to the average of the M2/GDP ratio, giving $\alpha=1.118$. The real marginal cost of Brazil's borrowing in international capital markets is given by the nominal Brady bond yield adjusted for US inflation, which equals $r=12.68 \%$ p.a.. A $50 \%$ share of tradables in consumption $\gamma$ is empirically reasonable for most countries, see De Gregorio, Giovannini and Wolf (1994). The value for the proportion of time spent working in steady state, $\bar{L}=1 / 3$, is based on the evidence cited in Cooley and Prescott (1995). We assume that this is the value associated with the high inflation steady state, and compute the larger value associated with low inflation from (11). Finally, the average length of price quotations of four quarters implied by $\delta=1 / 4$ is reasonable, see the evidence cited in Obstfeld and Rogoff (1996, chapter 10) and Taylor (1998).

Without loss of generality we normalize the tradables endowment to $y^{*}=\bar{L}=\bar{c}$, and initial net foreign assets to $f_{0}=0$. Note that for the purpose of presenting computed solution paths in Figure 1 we renormalize the initial steady state values of tradables and nontradables consumption to 1 . The log-linear specification of the utility index implies an intertemporal elasticity of substitution of one. Empirical estimates of this elasticity are typically below one, as in Reinhart and Vegh (1995). However, see Ogaki and Reinhart (1998) and Eckstein and Leiderman (1992) for examples of estimates closer to one. 


\begin{tabular}{|l|l|l|}
\hline Parameter & Value & Description \\
\hline$\varepsilon^{h}$ & $20 \%$ p.a. & Initial exchange rate depreciation \\
\hline$\varepsilon^{l}$ & $10 \%$ p.a. & Exchange rate depreciation during stabilization \\
\hline$\alpha$ & 1.118 & Inverse velocity \\
\hline$r$ & $12.68 \%$ p.a. & Real international interest rate \\
\hline$\gamma$ & 0.5 & Share of tradables in consumption \\
\hline$L$ & $1 / 3$ & Proportion of time spent working \\
\hline & & in the high inflation steady state \\
\hline$\delta$ & $1 / 4$ & Inverse of average contract length in quarters (4) \\
\hline
\end{tabular}

Table 1: Parameter Values

\section{Dynamic Response to Disinflation}

Figure 2 shows equilibrium paths for an unanticipated permanent inflation stabilization from $20 \%$ p.a. to $10 \%$ p.a. In a conventional Calvo-Yun sticky price model this would have no real effects, and aggregate inflation would immediately jump to $10 \%$. By contrast, in our model inflation $\pi$ does not immediately jump to the new lower steady state level. As can be seen in equation (31), this has two main reasons. The first is the lingering influence of historic price setting decisions on current aggregate inflation through the weighted average of past firm-specific inflation rates $\psi$. While $\psi$ immediately starts to decline it can only adjust slowly as and when additional firms revise their pricing policies. The second reason is the behavior of current price setters. Given the permanent nature of disinflation, the response of their updating rate $v_{t}$ is very strong, and consequently the extent of their front loading $p_{t}$ need not change very much. But $p_{t}$ is the second component of aggregate inflation. Inflation therefore also responds slowly because current price setters can spread their response to new information out over time, unlike in the Calvo-Yun model. 
The slow response of nontradables inflation combined with the immediately lower exchange rate depreciation implies that the real exchange rate appreciates sharply. In other words, the own real rate of interest on nontradables $r+\varepsilon-\pi$ initially falls sharply, giving rise to a downward sloping path of nontradables consumption. The lowest point, an output loss of around $2 \%$, is reached at the time nontradables inflation starts to undershoot exchange rate depreciation, thereby starting to depreciate the real exchange rate to its new equilibrium level. The nontradables recession is fairly long-lived at around a two-year duration.

In the new steady state nontradables output is permanently higher, reflecting the efficiency gain resulting from a reduction in the monetary distortion to the consumption-leisure choice, see equation (43). Disinflation therefore entails initial output costs and eventual permanent output gains. A welfare-theoretic evaluation of this trade-off is undertaken in Section 4.

\section{Welfare}

In analyzing the effects of disinflation policy in the previous section, it was found that there is a trade-off between costs due to an initial recession and benefits due to eventually smaller inflationinduced distortions to the consumption-leisure choice. The appropriate metric to evaluate this trade-off is the compensating variation in lifetime consumption introduced by Lucas (1987). The net welfare gain accomplished by a permanent reduction in the rate of exchange rate depreciation is defined as the fraction by which consumers' original steady state consumption basket $\bar{c}^{* \gamma} \bar{c}^{1-\gamma}$ would have to be increased to make them indifferent between their lifetime utility in the 

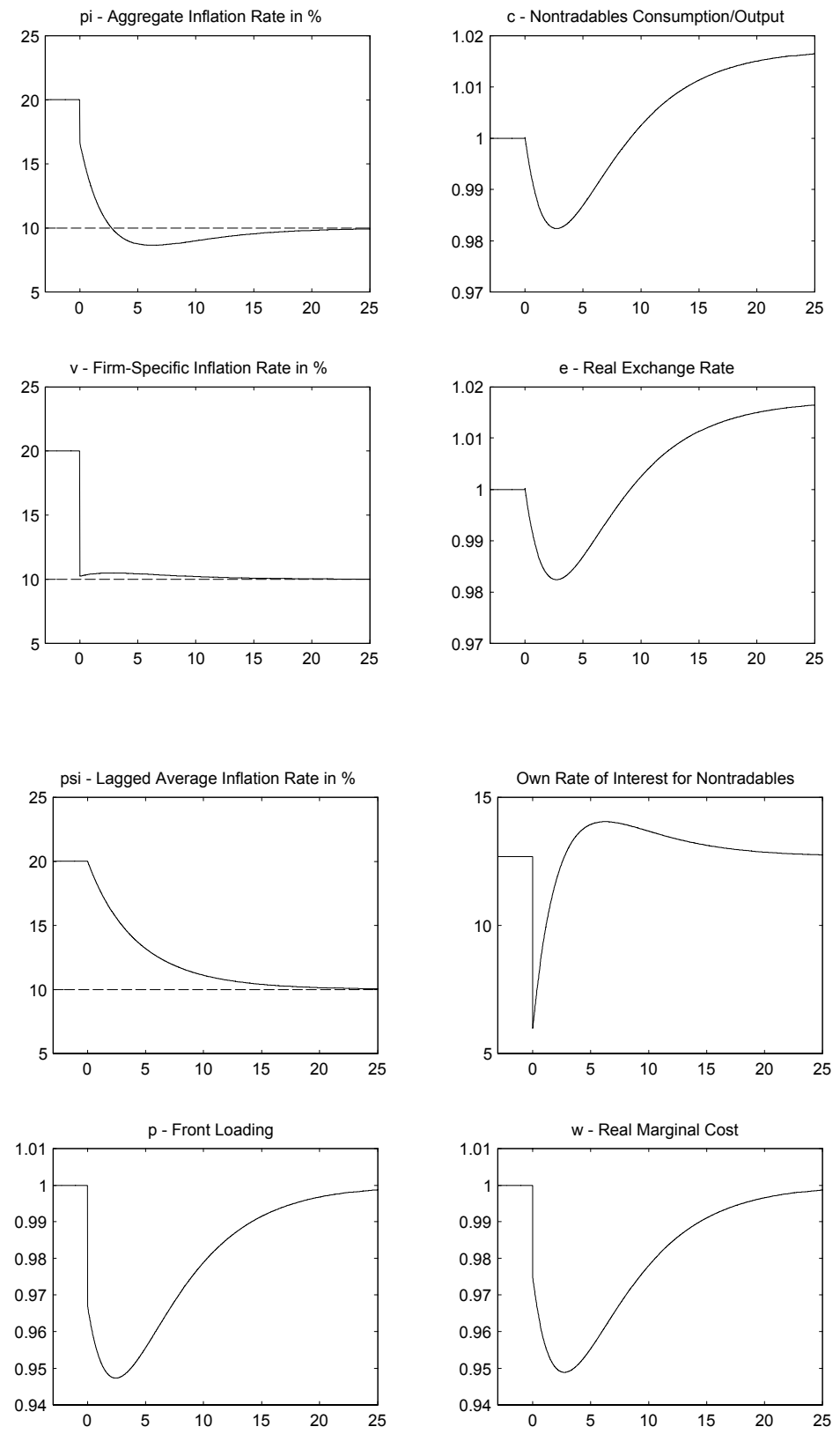

Figure 1 : Permanent Disinflation 
old, high inflation steady state and the lifetime utility achieved along the equilibrium path to the new, low inflation steady state. For the disinflation shown in Figure 1 this calculation produces a small welfare gain of $0.0272 \%$. That is a very small gain from a $10 \%$ reduction in inflation. Some further comments are therefore warranted. Most importantly, this is a net gain after taking account of the welfare costs of the nontradables recession. Furthermore, it is not clear that adding more features to the model would necessarily increase that gain significantly. On the one hand one may prefer to introduce different or even multiple monetary distortions, which would produce larger efficiency gains. But another reasonable generalization would be the introduction of wage stickiness, which could considerably increase the cost of the recession. Therefore, what we wish to emphasize in the current paper is the existence of a trade-off when disinflating under inflation inertia, rather than the precise welfare numbers obtained.

Next we explore the sensitivity of our welfare results to two parameters, the degree of price stickiness and the speed of disinflation. We parametrize the latter by considering gradual linear disinflation policies of the following form:

$$
\begin{array}{r}
\dot{\varepsilon}_{t}=-\eta \quad \text { for } t<\left(\varepsilon^{h}-\varepsilon^{l}\right) / \eta, \\
0 \text { for } t \geq\left(\varepsilon^{h}-\varepsilon^{l}\right) / \eta,
\end{array}
$$

where the parameter $\eta$ characterizes the speed of disinflation. The results are presented in Figure 2 below in terms of contours of net utility gains. The horizontal axis is the overall length of the disinflation period or degree of gradualism $\left(\varepsilon^{h}-\varepsilon^{l}\right) / \eta$ while the vertical axis is the average duration of pricing policies $1 / \delta$. The figure shows that, for reasonable average contract lengths of 
up to four quarters, a disinflation from $20 \%$ p.a. to $10 \%$ p.a. produces small net welfare gains of around $0.03 \%-0.05 \%$. These gains are always decreasing in $1 / \delta$, because the latter deepens and prolongs the nontradables recession. For any given $1 / \delta$ greater gradualism causes a milder real appreciation and therefore a shallower nontradables recession. But the downside of gradualism is the fact that the efficiency gains associated with the new less distorted steady state are realized later. At high $1 / \delta$ the first effect is stronger and greater gradualism improves welfare. But for lower $1 / \delta$ excessive gradualism starts to reduce welfare because the efficiency gains are delayed for too long. This is reflected in the fact that the welfare contours eventually bend downwards. Figure 2 suggests that for our chosen value of $\delta$ the length of the disinflation period should be quite short, between one and two years.

The same qualitative results hold for any size of disinflation in our model. Whether welfare is increased depends on the size of the monetary distortion, the average duration of pricing policies, and the degree of gradualism. Similar results will also hold if the monetary distortion is introduced in other ways as long as lower steady state inflation implies higher steady state welfare.

Finally, the minimum possible rate of steady state inflation is given by the Friedman rule $-r$, which is also the welfare maximizing steady state. This is in contrast to a recent literature ${ }^{14}$ which, using a framework where firms can only choose a price level, finds that the welfare maximizing steady state minimizes relative price dispersion and is therefore found close to zero inflation, not at the Friedman rule.

\footnotetext{
$14 \quad$ See e.g. Woodford (2002).
} 


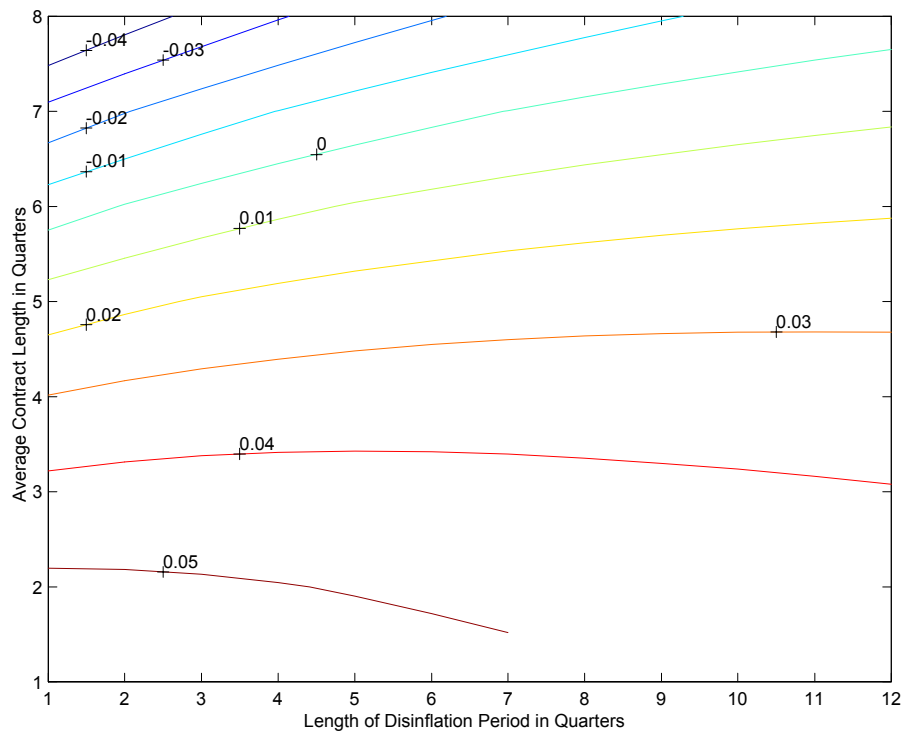

Figure 2: Welfare Gain Contours (\%)

\section{Conclusion}

This paper proposes a model of inflation inertia in an environment of maximizing, rational, forward-looking agents. It has set out one way to reconcile rational expectations staggered pricing models with important empirical regularities that have been hard to explain, namely inflation inertia and recessionary disinflations. In the proposed framework it becomes possible to conduct an explicit welfare analysis of disinflations that quantifies the trade-off between initial recessions and eventual efficiency gains. Under our parameterizations the latter were found to be always larger. As a by-product it was also shown that under our price-setting assumptions the Friedman rule continues to attain the optimal steady state. 
An attractive feature of this approach is that it accomplishes these objectives while otherwise remaining firmly within the 'New Keynesian' modelling tradition. This opens up rich possibilities for expanding an already large research agenda.

\section{Appendix A. The Relationship between Labor Supply and Nontradables Consumption}

We begin by defining the aggregate output index $y_{t}$ as

$$
y_{t}=\left(\int_{0}^{1} y_{t}(j)^{\frac{\sigma-1}{\sigma}} d j\right)^{\frac{\sigma}{\sigma-1}} .
$$

From the definition of equilibrium we know that $y_{t}(j)=c_{t}(j)$ and therefore $y_{t}=c_{t}$. Then (3) and (4) give us

$$
y_{t}(j)=y_{t}\left(\frac{P_{t}(j)}{P_{t}}\right)^{-\sigma} .
$$

Next we define the aggregate output quantity index $\tilde{y}_{t}$, using (12) and (37), as

$$
\tilde{y}_{t}=\int_{0}^{1} y_{t}(j) d j=\int_{0}^{1} l_{t}(j) d j=L_{t}
$$

and the alternative price index $\tilde{P}_{t}$ as

$$
\tilde{P}_{t}=\left(\int_{0}^{1} P_{t}(j)^{-\sigma} d j\right)^{-\frac{1}{\sigma}} .
$$

Then we can derive the following relationship from (A.1) - (A.4):

$$
L_{t}=\tilde{y}_{t}=\left(\frac{\tilde{P}_{t}}{P_{t}}\right)^{-\sigma} y_{t}=\left(\frac{\tilde{P}_{t}}{P_{t}}\right)^{-\sigma} c_{t} .
$$


This implies that the steady state relationship between labor supply and nontradables consumption/output is

$$
\bar{L}=\bar{c} .
$$

Furthermore, (A.5) can be linearized as

$$
\left(\ln L_{t}-\ln \bar{L}\right)=\left(\ln c_{t}-\ln \bar{c}\right)-\sigma\left(\frac{\tilde{P}_{t}}{P_{t}}-1\right) .
$$

Using (A.4) the linearization of the ratio $\tilde{P}_{t} / P_{t}$ can be shown to equal

$$
\left(\frac{\tilde{P}_{t}}{P_{t}}-1\right)=\int_{-\infty}^{t} \delta e^{-\delta(t-s)}\left(\left(p_{s}-1\right)-\int_{s}^{t}\left(\pi_{r}-v_{s}\right) d r\right) d s .
$$

But from (27) the right-hand side of this equation is zero. For the linearized system we therefore obtain the simple relationship

$$
\left(\ln L_{t}-\ln \bar{L}\right)=\left(\ln c_{t}-\ln \bar{c}\right) .
$$

\section{Appendix B. Roots of the Dynamic System}

The characteristic equation of system (47), for simplicity but without loss of generality evaluated at the original steady state $\bar{c}=1 / 3$, can be derived as

$$
\begin{gathered}
\lambda^{4}-2 r \lambda^{3}+\lambda^{2}\left(r^{2}-3 \delta(\delta+r)\right) \\
+\lambda\left(3 \delta^{2} r+3 \delta r^{2}\right)+\frac{3}{2}\left(\delta^{2}(\delta+r)^{2}\right)=0 .
\end{gathered}
$$

In the following we make use of Theorem 1.2.12 in Horn and Johnson (1985, p. 42). Let the $4 \times 4$ coefficient matrix in (47) be denoted by $A$, and the four roots by $\lambda_{1}, \lambda_{2}, \lambda_{3}, \lambda_{4}$. Then it must 
be true that

$$
\lambda_{1} \lambda_{2} \lambda_{3} \lambda_{4}=\operatorname{det}(A)=\frac{3}{2}\left(\delta^{2}(\delta+r)^{2}\right)>0 .
$$

There must therefore be zero, two or four roots with negative real part. Furthermore,

$$
\lambda_{1}+\lambda_{2}+\lambda_{3}+\lambda_{4}=\operatorname{tr}(A)=2 r>0 .
$$

This rules out the case of four roots with negative real part. For the final part of the proof, let $\chi_{x, y, z}$ be the $3 \times 3$ principal minor of $A$ associated with columns and rows $x, y$ and $z$. Then the theorem states that the following must hold:

$$
\lambda_{1} \lambda_{2} \lambda_{3}+\lambda_{1} \lambda_{2} \lambda_{4}+\lambda_{1} \lambda_{3} \lambda_{4}+\lambda_{2} \lambda_{3} \lambda_{4}=\chi_{1,2,3}+\chi_{1,2,4}+\chi_{1,3,4}+\chi_{2,3,4}
$$

For the sake of our argument, let the roots $\lambda_{3}$ and $\lambda_{4}$ have positive real parts. We compute the right-hand side and rewrite the left-hand side of (B.4) to get

$$
\left(\lambda_{1}+\lambda_{2}\right) \lambda_{3} \lambda_{4}+\lambda_{1} \lambda_{2}\left(\lambda_{3}+\lambda_{4}\right)=-3\left(\delta^{2} r+\delta r^{2}\right)<0
$$

The second term on the left-hand side is positive, and therefore we must have

$$
\lambda_{1}+\lambda_{2}<0
$$

This requires that these two roots be either real and negative or complex with negative real parts. As mentioned in the text, it can be established numerically that they are in fact real for all interesting parameter values. The same is true for the positive roots. 


\section{References}

[1] Akerlof G. and Yellen, J. (1985), "A Near Rational Model of the Business Cycle with Wage and Price Inertia”, Quarterly Journal of Economics, 100(5), 823-838.

[2] Ball, L. (1994a), “Credible Disinflation with Staggered Price Setting”, American Economic Review, 84, 282-289.

[3] Ball, L. (1994b), "What Determines the Sacrifice Ratio?”, in: Mankiw, N.G., ed., Monetary Policy (Chicago: University of Chicago Press).

[4] Ball, L. (1995), "Disinflation with Imperfect Credibility", Journal of Monetary Economics, 35, 5-24.

[5] Burstein, A. (2002), "Inflation and Output Dynamics with State Dependent Pricing Decisions", Working Paper, University of Michigan.

[6] Calvo, G.A. (1983), "Staggered Prices in a Utility-Maximizing Framework", Journal of Monetary Economics, 12, 383-398.

[7] Calvo, G.A., Celasun, O. and Kumhof, M. (2001), "A Theory of Rational Inflationary Inertia", forthcoming in: P. Aghion, R. Frydman, J. Stiglitz and M. Woodford, eds., Knowledge, Information and Expectations in Modern Macroeconomics: In Honor of Edmund S. Phelps (Princeton: Princeton University Press).

[8] Calvo, G.A. and Vegh, C. (1993), "Exchange Rate Based Stabilization under Imperfect Credibility", in: H. Frisch and A. Worgotter, eds., Open Economy Macroeconomics, 3-28 (London: MacMillan Press).

[9] Calvo, G.A. and Vegh, C. (1994), "Stabilization Dynamics and Backward-Looking Contracts", Journal of Development Economics, 43, 59-84.

[10]Calvo, G.A. and Vegh, C.A. (1999), "Inflation Stabilization and BOP Crises in Developing Countries", in: Taylor, J. and Woodford, M., eds., Handbook of Macroeconomics.

[11]Christiano, L.J., Eichenbaum, M. and Evans, C. (1996), "The Effects of Monetary Policy Shocks: Evidence from the Flow of Funds", Review of Economics and Statistics, 78(1), 16-34.

[12]Christiano, L.J., Eichenbaum, M. and Evans, C. (1998), "Monetary Policy Shocks: What Have We Learned and to What End?", NBER Working Papers, No. 6400.

[13]Christiano, L. J. Eichenbaum, M. and Evans, C. (2001), "Nominal Rigidities and the Dynamic Effects of the Shocks to Monetary Policy”, Working Paper, Northwestern University.

[14]Clarida, R., Gali, J. and Gertler, M. (1999), "The Science of Monetary Policy: A New Keynesian Perspective", Journal of Economic Literature, 37, 1661-1707.

[15]Cooley, T.F. and Prescott, E.C. (1995), "Economic Growth and the Business Cycle”, in Cooley, 
T.F., ed., Frontiers of Business Cycle Research (Princeton: Princeton University Press).

[16]De Gregorio, J., Giovannini, A. and Wolf, H.C. (1994), "International Evidence on Tradables and Nontradables Inflation", European Economic Review, 38, 1225-1244.

[17]Eckstein, Z. and Leiderman, L. (1992), "Seigniorage and the Welfare Cost of Inflation: Evidence from an Intertemporal Model of Money and Consumption", Journal of Monetary Economics, 29, 389-410.

[18]Erceg, C. J. and Levin, A. T. (2001), "Imperfect Credibility and Inflation Persistence”, Working Paper, Federal Reserve Board.

[19]Fuhrer, J. and Moore, G. (1995), "Inflation Persistence", Quarterly Journal of Economics, 110, 127-159.

[20]Gali, J. (2001), "New Perspectives on Monetary Policy, Inflation and the Business Cycle", forthcoming in Dewatripont, M., Hansen, L. and Turnovsky, S., eds., Advances in EconomicTheory (Cambridge: Cambridge University Press).

[21]Ghezzi, P. (2001), "Backward-Looking Indexation, Credibility and Inflation Persistence", Journal of International Economics, 53(1), 127-147.

[22]Gordon, R.J. (1982), "Why Stopping Inflation May Be Costly: Evidence from Fourteen Historical Episodes", in Hall, R.E., ed., Inflation: Causes and Consequences (Chicago: University of Chicago Press).

[23]Gordon, R.J. (1997), “The Time-Varying NAIRU and its Implications for Economic Policy", Journal of Economic Perspectives, 11(1), 11-32.

[24]Horn, R.A. and Johnson, C.R. (1985), Matrix Analysis (Cambridge: Cambridge University Press).

[25]Kumhof, M., Cespedes, L.F. and Parrado, E. (2002), "Macroeconomic Dynamics Under Inflation Inertia - An Optimizing Model", Working Paper, Stanford University and IMF.

[26]Lane, P. (2001), “The New Open Economy Macroeconomics: A Survey”, Journal of International Economics, 54(2), 235-266.

[27]Leeper, E.M., Sims, C. and Zha, T. (1996), "What Does Monetary Policy Do?”, Brookings Papers on Economic Activity, 2, 1-63.

[28]Lucas, R.E. Jr. (1987), Models of Business Cycles (Oxford, New York: Basil Blackwell).

[29]Mankiw, G. N. and Reis, R. (2002), "Sticky Information or Sticky Prices: A Proposal to replace the New-Keynesian Phillips Curve", forthcoming, Quarterly Journal of Economics.

[30]Obstfeld, M. and Rogoff, K. (1996), Foundations of International Macroeconomics (Cambridge, London: MIT Press). 
[31]Ogaki, M. and Reinhart, C.M. (1998), "Measuring Intertemporal Substitution: The Role of Durable Goods", Journal of Political Economy, 106(5), 1078-1098.

[32]Reinhart, C.M. and Vegh, C.A. (1995), "Nominal Interest Rates, Consumption Booms, and Lack of Credibility: A Quantitative Examination”, Journal of Development Economics, 46(2), 357-378.

[33]Rotemberg, J. (1982), "Sticky Prices in the United States”, Journal of Political Economy, 90, 1187-1211.

[34]Rotemberg, J. and Woodford, M. (1997), “An Optimization Based Econometric Framework for the Evaluation of Monetary Policy", NBER Macroeconomics Annual, 297-346.

[35]Sims, C. (1988), “Comments and Discussion”, Brookings Papers on Economic Activity, 1, 75-79.

[36]Taylor, J.B. (1980), "Aggregate Dynamics and Staggered Contracts", Journal of Political Economy, 88, 1-24.

[37]Taylor, J.B. (1998), "Staggered Price and Wage Setting in Macroeconomics”, NBER Working Paper, No. 6754.

[38]Woodford, M. (2001), "Imperfect Common Knowledge and the Effects of Monetary Policy", forthcoming in Aghion, P., Frydman, R., Stiglitz, J. and Woodford, M., eds., Knowledge, Information and Expectations in Modern Macroeconomics: In Honor of Edmund S. Phelps (Princeton: Princeton University Press).

[39]Woodford, M. (2002), "Inflation Stabilization and Welfare", Contributions to Macroeconomics, 2(1), Article 1.

[40]Yun, T. (1996), "Nominal Price Rigidity, Money Supply Endogeneity, and Business Cycles”, Journal of Monetary Economics, 37, 345-370.

[41]Zbaracki, M.J., Ritson, M., Levy, D., Dutta, S. and Bergen, M. (2000), "The Managerial and Customer Costs of Price Adjustment: Direct Evidence from Industrial Markets", Working Paper, Wharton School, University of Pennsylvania. 